\title{
Letter to the Editor concerning "New classification for the treatment of pyogenic spondylodiscitis: validation study on a population of 250 patients with a follow-up of 2 years" by Enrico Pola et al. Eur Spine J (2017) doi:10.1007/s00586-017- 5043-5
}

\author{
Ge $\mathrm{Chu}^{1} \cdot$ Diling $\mathrm{Wu}^{2} \cdot$ Siyang Huang ${ }^{3}$
}

Received: 28 April 2017/Accepted: 25 May 2017/Published online: 7 June 2017

(C) Springer-Verlag Berlin Heidelberg 2017

\section{Dear Editor,}

In their article, Pola et al. proposed a classification of pyogenic spondylitis as a guide to surgical management [1]. I would like to make the following observations in this regard:

The spine is a common site of infection and accounts for $2-7 \%$ of all the cases of musculoskeletal infections. Approximately $95 \%$ of pyogenic spinal infections involve the vertebral body and/or the intervertebral disc, with only $5 \%$ involving the posterior elements of the spine [2]. The most common site of infection is the lumbar spine, followed by the thoracic and cervical regions. This classification mainly includes typical pyogenic spondylitis. However, some atypical presentations such as atlanto-axial or posterior pyogenic spondylitis [2-4] do not find a place in the classification proposed by the authors.

\section{Compliance with ethical standards}

Conflict of interest None of the authors has any potential conflict of interest.

\section{References}

1. Pola E, Autore G, Formica V, Pambianco V, Colangelo D, Cauda R, Fantoni M (2017) New classification for the treatment of pyogenic spondylodiscitis: validation study on a population of 250 patients with a follow-up of 2 years. Eur Spine J. doi:10.1007/ s00586-017-5043-5

2. Cheung W, Luk KD (2012) Pyogenic spondylitis. Int Orthop 36:397-404

3. Ahlbäck S, Collert S (1970) Destruction of the odontoid process due to atlanto-axial pyogenic spondylitis. Acta Radiol Diagn 10:394-400

4. Lee KY (2014) Comparison of pyogenic spondylitis and tuberculous spondylitis. Asian Spine J 8:216-223

Siyang Huang

sy_huang1996@163.com

1 Department one of spine surgery, Traditional Chinese Medicine Hospital Affiliated to Xinjiang Medical University, Urumqi 830000, Xinjiang, People's Republic of China

2 Department of Intensive Care Unit, The Second Xiangya Hospital, Central South University, ChangSha 410008, Hunan Province, People's Republic of China

3 XiangXing College, Hunan University of Chinese Medicine, Changsha, Hunan Province, People's Republic of China 